\title{
RECALL OF REMOTE EPISODIC MEMORY IN AMNESIA
}

\author{
STUART ZOLA-MORGaN \\ Veterans Administration Medical Center, San Diego, CA and the Department of Psychiatry, University of \\ California School of Medicine, La Jolla, CA 92093, U.S.A. \\ NeAL J. COHEN \\ Department of Psychology, Massachusetts Institute of Technology, Cambridge, MA 02139, U.S.A. \\ and \\ LARRY R. SQUIRE \\ Veterans Administration Medical Center, San Diego, CA and the Department of Psychiatry, University of \\ California School of Medicine, La Jolla, CA 92093, U.S.A.
}

(Accepted 27 February 1983)

\begin{abstract}
Recall of remote episodic memory was assessed in three types of amnesic patient whose remote semantic memory had been evaluated previously. Patients with Korsakoffs syndrome, case N.A. and patients receiving electroconvulsive therapy all succeeded in recalling specific autobiographical episodes in response to single-word cues, and in many conditions performed as well as control subjects. Their pattern of performance generally paralleled that obtained in previous tests of remote semantic memory. These results argue against a view that amnesia reflects a selective deficit of episodic memory and suggest that the semantic-episodic distinction cannot illuminate the fundamental deficit in amnesia. Nor can the facts of amnesia confirm or deny the validity of this distinction in normal memory.
\end{abstract}

\section{INTRODUCTION}

RECENT experimental and theoretical work in psychology has considered a distinction between two types of memory, designated by Tulving [41] as semantic memory and episodic memory. Semantic memory is organized knowledge that an individual possesses about language and about the world, as distinct from and not including the experiences that led to the accumulation of that knowledge. Episodic memory is autobiographical information represented in memory in a way that is inextricably tied to the specific events or episodes that provided the source of that information. A memory is not episodic because it is autobiographical, e.g. memory of a friend's face is no more episodic than memory of a famous face. A memory is episodic because it includes information about "temporally dated episodes or events" [41]. The idea that memory is composed of these two systems has generated a considerable body of experimental work and discussion both in support of this idea [11, 12] and in criticism of it $[2,18]$. Recently, the distinction between semantic and episodic memory has been extended to the topic of human amnesia $[15,22,45]$. Specifically, it was noted that in amnesia there is preserved language and social skills as well as many examples of intact semantic knowledge about the world. Yet memory for the ongoing events or episodes of daily life is profoundly impaired. It was argued that amnesia constitutes a selective deficit in 
episodic memory and that the amnesic patient population provides a clear demonstration of the distinction between episodic and semantic memory.

One observation offered in support of this view was that patients with Korsakoff's syndrome were impaired in retrieving episodic memories from their past [15, 45]. Following the method used by CROviTz (e.g. [10]), patients were asked to recount specific episodes from their lives as responses to each of 20 common nouns (e.g. flag, bird, window). In such a task, patients with Korsakoff's syndrome were said to have had enormous difficulty generating specific memories in response to the cue words. For example, in response to the cue "flag" the best that one patient could apparently do was to state that "flags are for waving in parades" ([15], p. 278). Although this observation does support the claim that episodic memory is impaired in amnesia, it must be considered together with a large body of data indicating that semantic memory can also be impaired. Indeed, all formal tests of remote memory in the literature of human amnesia depend heavily on semantic memory. Thus tests of famous faces, famous voices, television programs or public events all require access to nonautobiographical, general knowledge about the world (see [7] for review of remote memory tests). Results from such tests have documented a clear deficit in patients with Korsakoff syndrome that is sometimes severe and extensive $[1,7,17,19,21,26]$. The fact that amnesic patients are impaired on tests of world knowledge would seem to create difficulties for the view that amnesia is a selective impairment in episodic memory. The present study addresses this view of amnesia as well as the larger issue of whether the semantic-episodic distinction can illuminate the nature of the deficit in amnesia. To these ends, we have assessed past autobiographical or episodic memory in three different types of amnesic patients for whom memory for world knowledge has already been thoroughly assessed.

\section{METHODS}

\footnotetext{
Subjects

Patients with alcoholic Korsakoffs syndrome. Seven patients with Korsakoffs syndrome residing in San Diego County participated in this study. This group of 4 men and 3 women averaged $50.7 \mathrm{yr}$ of age, with an average of 12.7 yr of education. Their average full-scale $1 Q$ was 101.3 and their average Wechsler memory scale score was 75.9 Neuropsychological screening and independent neurological evaluation indicated that memory impairment was the only remarkable defect of higher cortical function. All of these patients could draw a cube and a house in perspective, and none had aphasia or apraxia. These patients were given one form of the autobiographical memory test described below.

Case N.A. This patient has been severely amnesic for verbal material since 1960, when at the age of $22 \mathrm{yr}$ he sustained a stab wound to the brain with a miniature fencing foil $[14,40]$. Recent CAT scans have identified a lesion in the left dorsal thalamus of this patient in a position corresponding to the dorsomedial nucleus [33]. His memory deficit occurs despite above-average intelligence (WAIS, 124) and without any known defects in language or visuoperceptual ability. N.A. was tested on three separate occasions separated by at least one month using three different forms of the memory test described below. N.A.'s score was the average score obtained on the three tests.

Patients receiving bilateral electroconvulsive therapy $(E C T)$. This group consisted of 7 females and 3 males (mean age $=45.0 \mathrm{yr}$ ) prescribed ECT for relief of depressive illness. Six patients had received a previous course of treatment, but none within the previous 10 months. Patients were tested on two occasions, using different forms of the test, and thus served as their own controls. The first testing session occurred $6-10 \mathrm{hr}$ after the fourth or fifth treatment in the series, when amnesia is present as a relatively circumscribed disorder [28]. The second testing session occurred 35 months after treatment (mean $=\mathbf{3 . 5}$ months), when memory functions have substantially recovered [28]. Patients receiving ECT are sometimes prescribed drugs during their course of treatment. Previous studies of remote memory and ECT have found no relationship between prescribed drugs, drug dosage and performance on remote memory tests [37].

Patients receiving right unilateral ECT. This group consisted of 3 females and 5 males (mean age $=48.4 \mathrm{yr}$ ) prescribed right unilateral ECT for relief of depressive illness. Six patients had received a previous course of treatment, but none within the previous year (mean $=11 \mathrm{yr}$ ). Patients were tested on two occasions, using different forms of the test, and thus served as their own controls. The first testing session occurred $1-2$ days prior to the first treatment of the series and the second testing session began $45-80 \mathrm{~min}$ after the fifth treatment $($ mean $=65 \mathrm{~min})$.
} 
Right unilateral ECT is associated with considerably less anterograde and retrograde memory loss than bilateral ECT [28]. For example, right unilateral ECT does not affect performance on a remote memory test for T.V. programs that is affected by bilateral treatment [36]. Moreover, when impairment of memory for past events has been observed after unilateral treatment, it is less severe than after bilateral treatment [38].

Control group for patients with Korsakoffs syndrome. Four male and 3 female alcoholics were identified in San Diego County alcoholic treatment programs and served as control subjects for the present study. Their average drinking history was $23.9 \mathrm{yr}$, without history of head injury or liver disease, and they had been free of alcohol for an average of 10.4 weeks (range 2-24 weeks). The length of abstinence from alcohol did not relate significantly to performance on the remote memory test used in the present study [Spearman rank correlations ranged from -0.18 to +0.47 (mean $=+0.15$ ) for the scoring conditions to be described below]. One might wonder whether other characteristics of the alcoholic population might influence performance on memory tests, e.g. drugs prescribed or abused in addition to alcohol. However, hecause the alcoholic control group performed as well in this study as each of the other control groups, including a group of hospital employees, we tend to discount this possibility. They averaged $56.1 \mathrm{yr}$ of age and $12.3 \mathrm{yr}$ of education, and had WAIS subtest scores of 20.1 for information (Korsakoff patients $=14.7$ ) and 51.6 for vocabulary (Korsakoff patients $=47.1$ ). The alcoholic patients scored considerably better than the patients with Korsakoff's syndrome on tests of new learning (number of 10 paired associates learned during three trials: for alcoholics, 3.6, 7.6, 8.9; for Korsakoff patients, $0.5,0.8,1.5 ; 12$ min delayed prose recall: for alcoholics, 5.6; for Korsakoff patients, 0.2). The alcoholic subjects were tested with the same form of the test as the patients with Korsakoff's syndrome.

Control group for case N.A. Six male V.A. Medical Center employees served as control subjects. These subjects were matched to N.A. for age (mean $=40.2 \mathrm{yr}$ vs $43 \mathrm{yr}$ for N.A.), education (mean $=14.7 \mathrm{yr}$ vs $13 \mathrm{yr}$ for N.A.) and WAIS subtest scores (information: mean $=23.0$ vs 22.0 for N.A.; vocabulary: mean $=62.7$ vs 66 for N.A.). This group was tested on one of the three forms of the test that was given to N.A.

\section{Test and procedure}

The test of remote memory was based on one of autobiographical memory [10]. A list of 10 words was read to each subject one word at a time (e.g. flag, bird, window), with the instruction to recall a specific event from any time in the past that involved the stimulus word. Subjects were first asked to describe the memory and then to estimate as best they could when the event occurred. When subjects failed to provide a memory that was clearly specific to time and place, the experimenter probed to elicit the fullest possible response. Probing was employed to permit comparison with previous uses of this test $[15,45]$, and because our interest was in the status of remote episodic memory, not in the degree to which subjects failed to comply with instructions or were reticent to recall specific memories. Probing was done in two ways: (1) we encouraged the subject to be more specific about an already-stated more general memory, (e.g. "Okay, now you baby-sat for your niece on many occasions; I want you to try to remember one specific time" or "That's good, but I want you to try to pin it down to a specific time so that you could say something like 'I remember the time that such-and-such happened'"). (2) If a subject still could not produce an episode, we suggested to the subject samples of concrete possibilities which could be focused upon or which could serve as cues to aid the subject in generating a personal episode (e.g. "When you haby-sat was there a time that he got sick or something unusual happened?" or "Did you ever go some place with him or do something special like play a special game?"). All testing sessions were tape recorded and later transcribed for scoring.

\section{Scoring}

Four different scores were derived from each subject based on the transcribed protocols. First, a binary $(0 \cdots 1)$ scoring system was used. A 1 was awarded for each stimulus word that elicited a satisfactory, episodic memory and a 0 was awarded for each stimulus word that did not. Each subject's score for 10 words therefore ranged from 0 to 10 . This scoring system was based on the first answer offered by the subject for each word and ignored whatever might have been added with the help of the experimenter's probing. Second, the same binary scoring system was used, but with consideration given to any information elicited by the experimenter's probing. This version of the binary scoring system permitted comparison with previous uses of this test $[15,45]$.

Third, in order to increase the sensitivity of the test, responses were scored on a $0-3$ scale, based on the first answer offered by the subject for each word: 3 for an episodic memory [(i.e a memory for an event that took place at a place, such as "a time I saw (a particular) place"], 2 for a personal memory that hd some specificity, but that was not specific time and place, such as "a time I saw (a particular) event in (a particular) place"], 2 for a personal memory that had some specificity, but that was not recalled as an event in a particular time and place, and for which details are unavailable (e.g. "I saw a flag being burned on TV"), 1 for a vaguer reference to a memory involving no specific instantiation of the stimulus word (e.g. "I've seen flags at half-mast") and 0 for no responses or a generic response (e.g. "flags are for waving in parades"). Fourth, the same 0.3 scale was used, but taking into consideration any information elicited by the experimenter's probing. In this way both a binary $(0-1)$ and a more sensitive $(0-3)$ scoring system were used, with and without consideration of the effects of experimenter's probing for additional material. A response given a 1 under the binary system was given a 3 under the $0-3$ system. A response given a 0 under the binary could receive a 0,1 or 2 under the $0-3$ system. Thus the 0.3 system allows greater sensitivity in the evaluation of those responses that would have been assigned a 0 under the $0-1$ system. 
sessions of our seven patients with Korsakoff's syndrome and scored their responses under the four systems just described. The Spearman rank correlation coefficients for the two raters ranged from 0.91 to 0.97 across the four scoring systems.

\section{Recall of episodes}

\section{RESULTS}

Korsakoff patients $v$ s alcoholic control patients. Figure 1 shows the scores for all groups for four scoring systems. Separate analyses of variance for each scoring system (two groups $\times$ two conditions: with/without probing) revealed significant group effects for the $0-1$ scoring system $[F(1,12)=8.25, P<0.05]$ and for the $0-3$ scoring system $[F(1,12)=6.28$, $P<0.05]$. Analyses of main effects revealed that these differences were significant only when subjects were not probed to elicit full responses. For both the $0-1$ and the $0-3$ scoring system the two groups differed in the "without probe" condition $[F(1,24)=5.25, P<0.05$; $F(1,24)=5.17, P<0.05]$. In the "with probe" condition none of the differences between groups were significant $[F(1,24)=2.25, P>0.1]$. These findings mean that Korsakoff patients performed more poorly than the alcoholic subjects when only their first responses to each word were considered. Korsakoff patients performed similarly to alcoholic subjects when their responses were scored so as to allow for the beneficial effects of probing by the experimenter.

Case N.A. vs control group. N.A. was able to recall episodes, but nevertheless performed more poorly than his control group. N.A. was outside the $95 \%$ confidence interval of his

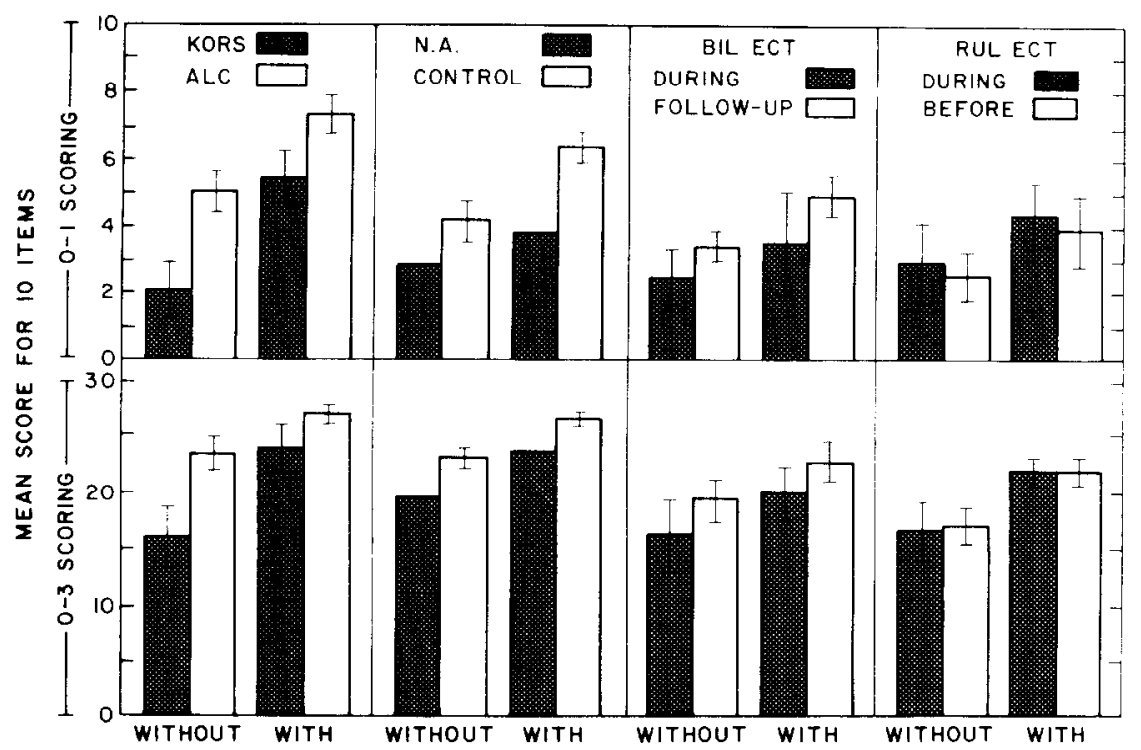

FIG. 1. Scores (mean + S.E.M.) on a 10-item test of past, episodic memory obtained under four different scoring systems by patients with Korsakoffs syndrome (KOR, $n=7$ ), alcoholic control subjects (ALC, $n=7)$, case N.A., control subjects for N.A. $(n=6)$, patients receiving bilateral ECT (BIL ECT, $n=10$ ) and patients receiving right unilateral ECT (RUL ECT. $n=8$ ). BIL. ECT patients were tested after the fifth treatment and again several months later. RUL ECT patients were tested before treatment and again after the fifth treatment. All subjects were scored under a 0 l system ( maximum score $=10$ ) and under a $0-3$ system (maximum score $=30$ ). Each scoring system was applied to the first response given without the benefit of questioning and probing (WITHOUT) and to the response obtained with questioning and probing by the examiner (WITH). 
control group in all conditions, except when his responses were scored under the $0-1$ system without allowing for the benetits of probing by the experimenter. Both N.A. and his control group benefited from the effects of this probing.

Bilateral ECT. Separate analyses of variance were done for each scoring condition, using the factors testing occasion (during/follow-up) and test condition (with/without probes). Although there was a tendency for patients receiving bilateral ECT to score somewhat more poorly during their course of treatment than when tested 3-5 months later, these differences did not approach significance under either the $0-1$ scoring $[F(1,9)=1.45, P>0.1]$ or the $0-3$ scoring $[F(1,9)=3.19, P>0.1]$. Three patients tested during ECT failed to receive any 3point scores, and these patients did improve their performance at follow-up. However, two other patients received more 3-point scores during ECT than at follow-up. Based on the 0-3 scoring system the average scores obtained during ECT were 16.5 (without probes) and 20.2 (with probes). The corresponding scores obtained as follow-up were similar (19.2 and 23.0). Thus bilateral ECT did not have a measurable effect on the ability to recall episodic memories.

Right unilateral ECT. Patients receiving right unilateral FCT performed similarly before treatment and $1 \mathrm{hr}$ after the fifth treatment (for both the $0-1[F(1,7)=0.443, P>0.5]$ and the $0-3$ scoring system $[F(1,7)=0.17, P>0.5])$. Thus right unilateral ECT had no effect on recall of episodic memories.

\section{Sample episodes}

To illustrate the episodic nature of the memories recalled by the seven Korsakoff patients, we have taken six representative episodes from six different patients in the Korsakoff group (Table 1). These six episodes were drawn from a total of 38 , all of which had received a score of 1 under the $0-1$ system and 3 under the $0-3$ system. The examples demonstrate that these patients were capable of making specific and detailed responses to the stimulus words. Indeed, the 38 responses of the Korsakoff group that received a full score were indistinguishable in quality and in degree of detail from the 51 responses of the alcoholic subjects that received a full score. We also examined all 10 responses of each patient with Korsak off's syndrome to determine the character of those responses that did not receive full credit as an episodic memory. Generic or descriptive responses such as "flags are for waving in parades" would have received a score of 0 under the $0-3$ scoring system. Out of 70 responses ( 7 Korsakoff patients $\times 10$ stimulus words), only 2 received a 0 score; in these cases the patients were unable to recall any material at all. Thus no patient was limited to generic, descriptive responses about the stimulus words. Ten of the 70 responses by the Korsakoff patients (and none by the alcoholics) received a score of 1 under the $0-3$ scoring system, i.e. they were limited to vague memories involving the stimulus word: "I used to salute the flag" or "I've drunk Pepsi from a bottle". Twenty of the responses offered by the Korsakoff patients (and 19 by the alcoholics) were more specific, but without a clear indication on further questioning that a specific event or episode was being remembered. These responses received a score of 2, e.g. "I once fixed a gate with nails" or "I remembered buying a 50-star flag in San Diego when they first came out" or "I remember reading Treasure Island which was my favorite book".

In summary, the data from Fig. 1 suggest that all the amnesic patients were successful in recalling episodic memories. Patients with Korsakoff's syndrome were as capable of recalling episodic memories as alcoholic control subjects when their scores were based on full responses elicited during probing by the experimenter. Consideration of the responses by the 
Table 1. Recall of episodic memory by patients with Korsakoff's syndrome*

Ticket: I didn't get the ticket but I remember one time . . My wife got the ticket when I was with her and this cop was about two-forty and he said she changed lanes in the circle that she was going around; that she came in off the street in the outside lane and wound up on the inside lane, and she said she didn't . . he was gonna give her a ticket and that's when the fight started ... my little bitty woman and that great big man ... hah. hah. he didn't give her a ticket; he got to laughin at her so damn much . . . she cut into him, she was so damn mad ... [Did she try to hit him?] Yeah, Yeah [What were you doing all this time?] Sittin' there in the car laughin' myself silly, cause he was big enough to put both of us in his pocket and forget us. . lie looked at unt: and I said to her ... you can stand there and hit him for a week before he'd realize it ... so we got to talkin about her and he didn't write out the ticket.

Picture: I have always admired artwork and always inter ested in it. This was when I was still livin' with my kids" father in Kentucky. It was after we bought the house and got it all painted and fixed up and I had, we had a double door between the living room and the bedroom. So I had done three walls and the ceiling in pale gray and this one wall in charcoal, where the double doors were, and I was at the store shoppin' around where I had a charge account and I saw these two murals. They were very classy and they weren't dirty but they were nude ladies. They were to fit on either side of the door. So I got 'em and took 'en home to hang on those two walls. And 1 hung 'em in hopes that they would meet approval. And my husband saw 'em and swore and bedamned that I had posed for the things so he took one down. threw it on the floor and stomped it. I was heart-broken.

Window: I shot a BB gun at a grocery store window when I was a kid about 10. [Was it an accident?] No, I just did it: I thought that BBs would bounce off, but there was a chip in the window, you know, on the inside. [Was the store open?] No, it was closed. [What time of day?] About eight in the morning. It was on a Sunday. That's why it was closed. [Anyone catch you?] Damn right! The owner. [How"] Asked around and found out it was me. [What happened?] My dad had to pay for a new window.

Baby: My first born . . . my daughter. I was sitting with my wife in the labor room for seven hours. [Did you see the birth?] No, they wouldn't let me, but $I$ sat with her in the labor room and saw the baby after it was cleaned up and everything ... [Do you remember when you first saw the baby?] . . it was about an hour after, red and purple color... I thought she was cute.

Baby: I remember one time, I can't tell you how old I was. + but I remember going through the woods and ran across a nest in the path going through the woods and in it were four or five baby birds that just musta been just born, you know, 'cause they were all just skin and bones and no feathers on 'em. I couldn"t find out where they came from or what tree they fell out of. so I took 'em home with me and raised 'em at home. We had a beatiful hickory nut tree in the backyard and I climbed up the tree and made a, you know. I had these boards across where you can walk up the trunk of a tree, and I placed 'em in sort of a cross branch and, I dunno, some other bird came along and adopted 'em later and they flew away.

Book: When C. and I got home; like I said we went from here to Denver by bus. C. suggested that I call them up and I did. They came to meet us at the bus station, my brother, sister and brother-in-law. C. had met everyonc except J. and he didn't know J. from Adam. And we're look in' all over the bus station and I says. "Darn, where are they?" He says, "I kinda remember your sister but I never met your brother." And I says, "Well, put it this way, he's real tall." And then he came in and I said "there he is" and I rushed over and hugged him and when I did he gave me a book and on the back of the book was his picture. If you go to the library you'll find that oul.

* Brackets enclose questions by examiner.

tPatient said she was unsure of her age, but believed she was $\& 10 \mathrm{yr}$ old.

Korsakoff group that received partial credit provided further evidence of the ability of this group to respond appropriately to the task and to elicit memories. On no occasion was a patient limited to a generic response about the stimulus word, e.g. "flags are for waving in parades". Case N.A. performed consistently more poorly than his comparison group, though even he was capable of considerable recall.

\section{Dating of episodes}

We next asked whether the amnesic patients might have differed from the comparison groups with respect to the time periods to which the successfully remembered events belonged. Figure 2 shows the age of these memories. Here, recall in each time period is presented as a percentage of the total number of memories elicited. In this way the temporal 

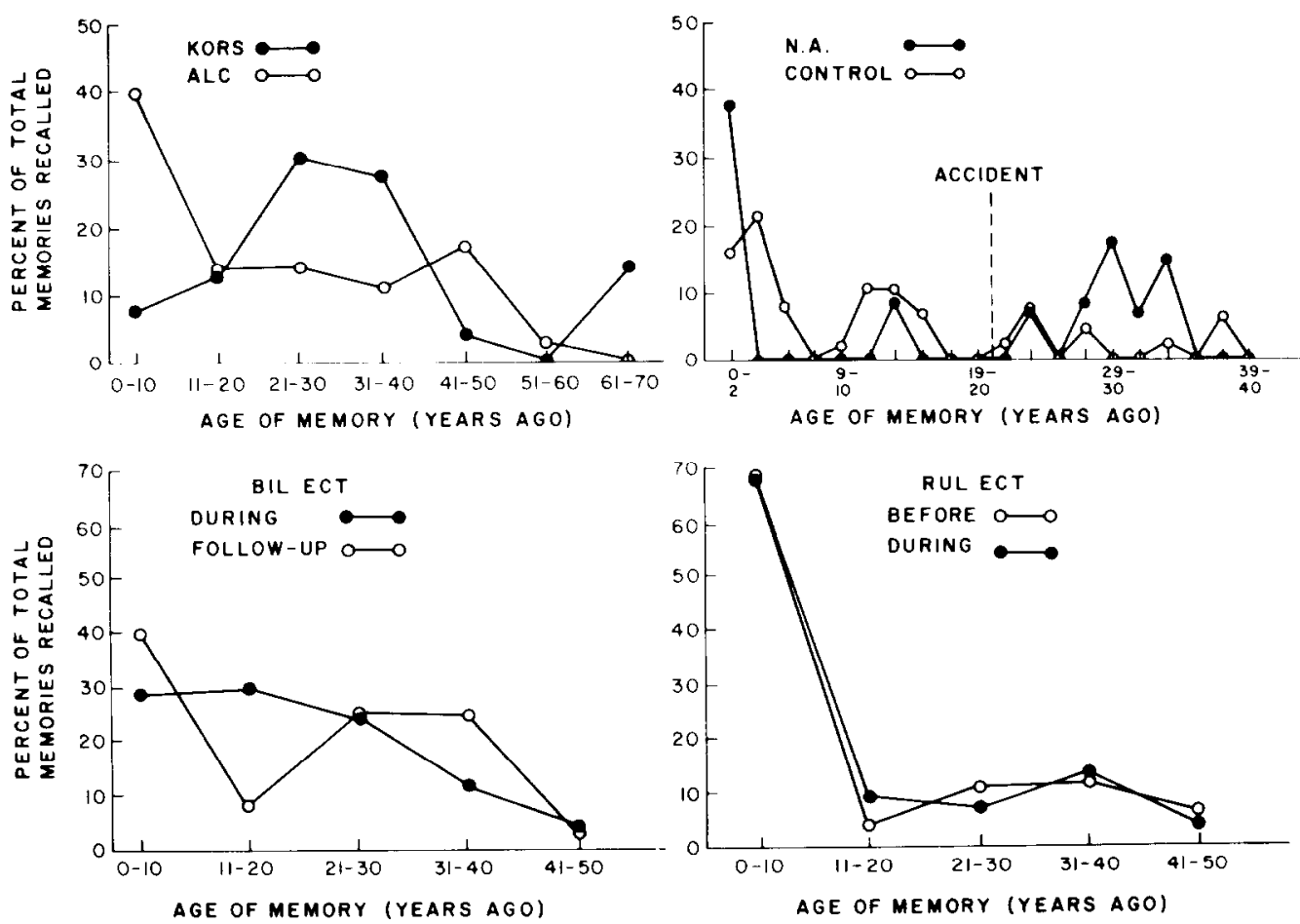

FIG. 2. Percentage of total memorics recalled in each past time period by patients with Korsakoffs syndrome (KOR, $n=7$ ), alcoholic control subjects (ALC, $n=7$ ), case N.A., control subjects for N.A. $(n=6)$, patients receiving bilateral ECT (BIL ECT, $n=10)$ and patients receiving right unilateral ECT (RUL ECT, $n=8$ ). This analysis was based only on those memories given full credit as an episodic memory.

characteristics of amnesic performance could be evaluated independently of the number of memories recalled. This analysis included all responses that had received a score of 1 under the $0-1$ scoring system and 3 under the $0-3$ system.

Korsakoff patients $v$ s alcoholic control subjects. As Fig. 2 shows, patients with Korsakoff's syndrome drew their memories from further in the past than the alcoholic control subjects. An analysis of variance revealed a significant effect of decade $[F(6,72)=2.47, P<0.05]$, indicating that memories were not recalled from all decades with equal frequency. The significant interaction of group $\times$ decade $[F(6,72)=2.77, P<0.05]$ indicated that the two groups differed with respect to which decades yielded memories. For alcoholic subjects the average age of memories was $20.1 \mathrm{yr}$; for Korsakoff patients $30.4 \mathrm{yr}$.

Case N.A. vs control group. For this comparison we have shown the percentage of memories recalled from each 2 -yr period during the past $40 \mathrm{yr}$. The control subjects recalled more memories from recent time periods and fewer memories from more remote time periods. The average age of their memories was $12.7 \mathrm{yr}$. N.A.'s performance was striking in that all of his memories save one came from either the most recent time period (in fact, from the 9 months preceding testing) or from the period prior to his accident in 1960. Thus N.A. either recalled memories that were relatively recent or he recalled memories from a period that began when he was $10 \mathrm{yr}$ old and ended when he was $20 \mathrm{yr}$ old, $2 \mathrm{yr}$ prior to his accident. 
These results for N.A. point out the usefulness of this testing method for exploring the temporal features of amnesia in individual subjects. The same point has been made recently for amnesias of psychogenic origin [24].

Bilateral ECT. Figure 2 shows the percentage of memories recalled from the past 5 decades for patients tested during their course of treatment and again 3-5 months later. The percentage data shown in Fig. 2 for bilateral ECT excluded those three patients who did not receive any 3-point scores. An analysis of variance yielded no significant effects of decade $[F$ $(4,48)=2.14, P>0.1]$ or of testing occasion $\times$ decade $[F(4,48)=0.80, P>0.1]$. During their course of treatment, the average age of the memories reported by the patients was $17.0 \mathrm{yr}$. Three to five months later the average was $17.5 \mathrm{yr}$.

Although grouping responses by decades did not reveal an effect of bilateral ECT on which time periods yielded memories, it seemed possible that a finer analysis of past time periods might reveal some effect. Bilateral ECT can produce a temporally limited retrograde amnesia, whereby memory for news events or television programs that occurred $1-2 \mathrm{yr}$ before treatment is impaired but memory for events that occurred prior to that time is not affected $[7,30,35,36]$. Accordingly, we asked whether bilateral ECT noticeably reduced the probability of recalling episodic memories from the most recent $2 \mathrm{yr}$.

In the control condition, 3-5 months after treatment, a total of 17 memories (involving 6 of the 7 patients who recalled episodes) were dated within the past $2 \mathrm{yr}$. Sixteen of these were placed within the previous 5 months. In the amnesic condition $6-10 \mathrm{hr}$ after four or five treatments, a total of eight memories (involving three of the same seven patients) were dated within the previous 2 yr. However, six of these eight memories were due to one individual, who placed them within the past 2 weeks. None of the six other patients placed any memories within the previous 11 months. Although these data are not sufficient to reach a firm conclusion, they seem consistent with our expectation, based on other studies, that bilateral ECT can reduce the ability to recall information acquired during the previous $1-2 \mathrm{yr}$.

Right unilateral ECT. The average age of the memories reported by the patients was $10.9 \mathrm{yr}$ before ECT and $10.4 \mathrm{yr}$ after the fifth treatment of the series. There was an effect of decade $[F$ $(4,56)=20.78, P<0.01]$, indicating that the events recalled tended to belong to more recent time periods than to old time periods, but the effects of testing occasion $[F(1,14)=1.27]$ and testing occasion $\times$ decade $[F(4,56)=0.12]$ did not approach significance.

\section{DISCUSSION}

The results can be summarized by saying that the amnesic patients were capable of recounting episodic memories from their past and in some cases were able to do this as well as the control subjects. Patients receiving right unilateral or bilateral ECT scored as well shortly after ECT, at a time when memory impairment can be detected by formal tests, as they did either before treatment or a few months later. Patients with Korsakoff's syndrome performed more poorly than alcoholic control subjects when only their initial responses to the stimulus words were considered. However, they performed as well as the control subjects when scoring also considered information elicited in response to the experimenter's probing. Finally, N.A. performed more poorly than his matched control group.

\section{Testing episodic memory in amnesia}

When data are based on patient narratives and on decisions by raters about what constitutes an episodic memory, it is important to be explicit about the criteria used, to 
identify any limitations intrinsic to the experimental methods and to note any ways in which the methods themselves could account for different findings among studies. In Table 1 we have presented several examples of the responses offered by patients with Korsakoff's syndrome that were scored as satisfactory episodic memories. Clearly, the amnesic patients were capable of more than generic or descriptive statements about the stimulus words. In part, their success in recalling episodes was due to the rigorous probing that was used throughout the study and that was successful in eliciting detailed episodes from almost all patients. Except for differences in the time period to which the remembered events belonged (see below), we were unable to distinguish the episodes recalled by the amnesic patients from those recalled by the control groups. Nevertheless, we cannot prove that the nature of the episodes offered by the amnesic patients were the same in every respect as those offered by the comparison groups. It would also be difficult to rule out the possibility that some responses were fabricated. However, contrary to popular belief, confabulation is not common in the chronic form of Korsakoff's syndrome [39], and we had no reason to suspect fabrication in any other group. Previous studies of amnesic patients using this method $[15,45]$ also used probes in an attempt to elicit as complete a response as possible. Indeed, the methods that have been used in this study and previous ones seem similar. It is worth mentioning, however, that the word "flag", which has been used as an example to show how amnesic patients "with few exceptions ... do not retrieve individual events at all" ([15], p. 278), is not a representative word in this episodic memory task. In our study the stimulus word "flag" yielded a lower score among both Korsakoff patients and alcoholic control subjects than any of the other words.

\section{Comparison of remote semantic and episodic memory in amnesia}

The present study of remote episodic memory was administered to three types of amnesic patient whose remote semantic memory we had previously evaluated in detail [7, 31]. In this way we were able to compare the status of these two kinds of memory in amnesia. Previous results with tests of remote semantic memory have demonstrated two kinds of deficit: extensive remote memory impairment covering many past decades and relatively brief or temporally limited retrograde amnesia covering a few years [7, 27, 31].

Extensive remote memory impairment: Korsakoff's syndrome. Patients with Korsakoff's syndrome have an extensive impairment in remote memory that is most severe in recent time periods $[1,3,7,17,19,26]$. It seemed reasonable to expect that patients with Korsakoff's syndrome would have difficulty recounting episodic memories from these same time periods. Indeed, the only other study of remote episodic memory in organic amnesia reported patients with Korsakoff's syndrome to be profoundly impaired [15, 45]. This study, however, shows that patients with Korsakoff's syndrome can recall episodic memories. they apparently accomplish this by reaching further into the past than alcoholic control subjects (see Fig. 2), drawing memories from time periods that were also less affected in tests of remote semantic memory. Performance by Korsakoff patients may have been as good as it was because, in contrast to the requirements of remote semantic memory tests, this test of remote episodic memory permitted patients to base their recall on whichever past time periods they chose and to select any memories within those time periods.

A deficit was apparent in the Korsakoff patient group when scoring was based only on a subject's first response to each stimulus word, without consideration of the effects of probing. Hence probes were particularly effective in eliciting episodic memories in this group. To 
determine what aspect of probing was effective in eliciting episodic memories, we have examined all instances when the Korsakoff patients or the alcoholic control subjects were unable initially to produce an episodic memory but did succeed with the help of probing by the experimenter. We found that the majority of interactions with the subjects by the experimenter were non-specific, e.g. they constituted encouragement or the repeating of instructions $(65 \%$ for alcoholics, $58 \%$ for the Korsakoff group). Importantly, these interactions did not generally provide specific retrieval strategies or cues to help subjects generate episodes. We therefore suggest that the effect of the probes was to counteract the loss of initiative so often noted in these patients [38].

Extensive remote memory impairment : case N.A." Previous studies of remote semantic memory have indicated that case N.A., who has diencephalic amnesia, has good memory for events that occurred prior to his accident in 1960 [7, 32]. In one study [7] his performance for the period prior to 1960 was normal in six out of seven tests but measurably impaired in one test involving detailed recall of past public events. In this study of episodic remote memory, N.A. was also impaired relative to his control group, though this impairment was a mild one and he was able to produce a good number of episodic memories. We previously considered that N.A.'s deficit in one test of semantic remote memory for public events might be due to his anterograde amnesia since 1960 [7]. That is, N.A.'s poor recall of public events from the 1940 s and the 1950s could reflect his social isolation since 1960 and his failure to learn and integrate additional information about these events after that time. The present finding that N.A. also had difficulty in recalling autobiographical memory seems to argue against this possibility. Although his long-standing anterograde amnesia should make it difficult for him to recall episodic memories from the interval 1960 to present, it is not clear why his anterograde amnesia should have affected his ability to recall memories from the premorbid period, prior to 1960 . On the one hand, one might suppose that during the period of his anterograde amnesia he has been unable to use daily events to prime or strengthen memories of previous events, as normal subjects may do. On the other hand. we must also consider the possibility that N.A. has a real impairment of remote memory, albeit a mild one that is not detectable by many tests of remote memory. A degree of impairment in remote memory might therefore be a regular feature of diencephalic amnesia. These issues could be investigated further by the careful study of patients with diencephalic amnesia of recent onset and of patients with bitemporal amnesia who have had their amnesia for a long time.

Temporally limited retrograde amnesia. The second form of remote memory impairment identified previously is temporally limited retrograde amnesia, which involves the loss of information acquired within the previous few years without the loss of information acquired before that time $[27,31]$. This form of amnesia has been associated with bitemporal amnesia, e.g. case H.M. [25]. In addition, patients receiving bilateral ECT exhibit temporally limited retrograde amnesia $[7,30,35,36]$. Clearly, amnesic patients with this form of remote memory impairment should have little difficulty in recounting cpisodic memories. They should be able to overcome whatever deficit they have by drawing memories from time periods prior to the affected periods. Patients receiving ECT confirmed these expectations: (1) shortly after ECT, patients recalled as many episodic memories as before ECT or several months later; and (2) whereas before bilateral ECT six patients recalled episodic memories from within the previous 5 months, after ECT only onc patient recalled any episodic memories from within the previous 11 months. Taken together, the present findings concerning recall of remote episodic memory in amnesia parallel previous findings for remote semantic memory, and they are consistent with our earlier description of two kinds of remote memory impairment 
$[7,31]$. The findings presented here do not support the view that semantic and episodic memory are separated or dissociated in amnesia.

\section{Recall of remote episodic memory in amnesia}

The major finding of this study is that amnesic patients were remarkably good at recounting cpisodic memories. We have found no evidence for a selective deficit in episodic memory in amnesia. Indeed, patients performed at least as well on this test of remote episodic memory as they had performed previously on tests of remote semantic memory. Two issues are worth considering when contrasting our findings with the apparently widespread impression that amnesia is associated with a loss of the ability to recall episodic memory. First, that impression is based only on the Korsakoff patient (but see [46] for a single case study that gives a different impression of the Korsakoff patient). Until now these issues have not been addressed at all in patients receiving ECT or in other forms of amnesia.

Several recent studies have shown that Korsakoff's syndrome can be associated with cognitive deficits not exhibited in other forms of amnesia [20,29], suggesting that one must be cautious in making generalizations about amnesia based on Korsakoff's syndrome. Second, even among patients with Korsakoff's syndrome one must be cautious in making general statements, because the Korsakoff population itself is heterogeneous.

This heterogeneity may help to explain how the data presented here could be divergent with findings from such patients in other settings. Different Korsakoff patient groups have been shown to be either normal or abnormal in some tests $[4,20,29,44]$, even when tested with the same material in the same laboratory [29]. Moreover, Korsakoff's syndrome is associated with variable neuropathology $[16,43]$. Accordingly, difficulty in recounting episodic memory by any particular group of patients must be considered with care. Because the group of patients studied here succeeded in recalling episodic memories, we suggest that when Korsakoff patients have difficulty with this task, they may have some cognitive deficit in addition to the basic memory disorder. In any case, impaired episodic memory for remote events is not obligatory to Korsak offs syndrome or to other forms of amnesia, and inferences about amnesia and the nature of normal memory cannot be based on such an impairment.

\section{Amnesia and the distinction between semantic and episodic memory}

Previous statements in the literature about the usefulness of the semantic-episodic memory distinction for understanding amnesia seem to have been confused by the temporal features of amnesia, as we have discussed elsewhere $[7,27,31]$. Thus amnesia has sometimes been characterized as a loss of the ability to remember the (episodic) events of daily life, despite intact ability to remember general (semantic) knowledge about the world. This description of amnesia, albeit accurate, cannot provide support for the semantic-episodic distinction because it is confounded by differences in the time periods from which the two classes of memory are drawn. For example, remembering events of last Tuesday requires that an individual has access to recently acquired information, whereas remembering that the capital of France is Paris involves access to information acquired a long time ago. This difference is important because amnesia typically impairs the ability to acquire new information and spares the ability to recall information acquired in early life. When these temporal features of amnesia are taken into account, two points about semantic and episodic memory in amnesia become clear: (1) as measured by memory tests about information in the 
public domain, semantic memory can be markedly affected in amnesia, especially for memory acquired during recent time periods $[3,7,31] ;(2)$ as demonstrated in the present study, episodic memory can be spared in amnesia, especially for memory acquired during more remote time periods. These facts argue against the usefulness of the semantic-episodic distinction for understanding amnesia. A similar point of view has been stated recently by HuPPERT and PierCy [13].

This line of argument does not, of course, deny the usefulness of the semantic-episodic distinction to discussions of normal memory, nor its possible relevance to some kinds of disordered memory such as amnesia of psychogenic origin [24]. In addition, the attempt to apply such a proposal to the pattern of deficits in amnesia has been of value in focusing attention on the contrast between the memory tasks that amnesic patients can and cannot perform. Thus, despite their severe impairment in learning and memory, amnesic patients are able to learn a variety of perceptual-motor skills, as well as perceptual skills like mirrorreading and cognitive skills like the solution to the Tower of Hanoi puzzle [5, 6, 8, 9, 45]. Consideration of these data has suggested to us a different framework, one that hypothesizes a fundamental difference between the learning of declarative knowledge, which is impaired in amnesia, and the learning of procedural knowledge, which is spared. How this distinction differs from the semantic-episodic distinction, and its success in accounting for the data of human amnesia, are considered elsewhere $[8,27,32]$. It should be emphasized here that what has been termed declarative knowledge applies to both episodic and semantic memory. By this view, recall of episodic memory is possible in amnesia because episodes can be drawn from time periods prior to those that are affected in amnesia or from those that are least affected. Tulving, ScHACTER and their colleagues have also argued that the semantic-episodic distinction as originally formulated concerned only propositional knowledge and did not consider skill learning and other examples of procedural knowledge $[23,42]$. The distinction between declarative and procedural knowledge can account for data that have been used in support of the semantic -episodic distinction, and should prove useful both in understanding the nature of the deficit in human amnesia and in specifying the contribution of the affected brain regions to normal memory functions.

Acknowledgements - Supported by the Medical Research Service of the Veterans Administration and by NIMH Grant MH 24600. We thank Anne Reilly, Brian Leonard and Armand Bernheim for research assistance.

\section{REFERENCES}

1. Albert, M. S., Butters, N. and Lfvin, J. Temporal gradients in the retrograde amnesia of patients with alcoholic Korsakoff's disease. Arch. Neurol. 36, 211-216, 1979

2. Anderson, J. R. and Ross, B. H. Evidence against a semantic-episodic distinction. J. exp. Psychol.: Human Learning and Memory 6, 441-466, 1980.

3. Butters, N. and AlBert, M. S. Processes underlying failures to recall remote events. In Human Memory and Amnesia, L. S. Cermak (Editor), pp. 257-274. Lawrence Erlbaum, Hillsdale, NJ, 1982.

4. Butters, N. and Cermak, L. S. Some comments on Warrington and Baddeley's report of normal short-term memory in amnesic patients. Neuropsychologia 72, 283-285, 1974.

5. COHEN, N. J. and CORKIN, S. The amnesic patient H.M.: learning and retention of a cognitive skill. Soc. Neurosci. Abstr. 7, 235, 1981.

6. Cohen, N. J. and Souire, L. R. Preserved learning and retention of pattern analyzing skill in amnesia: dissociation of knowing how and knowing that. Science 210, $207-209,1980$.

7. COHEN, N. J. and SQuire, L. R. Retrograde amnesia and remote memory impairment. Neuropsychologia 19, $337-356,1981$. 
8. Cohen, N. J. and Squire, L. R. Preserved learning capacity in amnesia: evidence for multiple memory systems. In The Netropsychology of Memory, N. ButTtFrs and L. Sou JRF. (Editors). Guilford Press, New York, in press.

9. CoRkin, S. Acquisition of motor skill after bilateral medial temporal lobe excision. Neuropsychologia 6, $255-265,1968$.

10. Crovitz, H. F. and SChiffman, H. Frequency of episodic memories as a function of their age. Bull. Psychonom. Soc. 4, 517-518, 1974

11. Hermann, D. J. and Harwood, J. R. More evidence for the existence of separate semantic and episodic stores in long-term memory. J. exp. Psychol.: Human Learning and Memory 6, 467-478, 1980.

12. HermanN, D. J. and MCLaughin, J. P. Effects of experimental and pre-experimental organization on recognition: evidence for two storage systems in long-term memory. J. exp. Psychol. 99, 174-178, 1973.

13. Huppert, F. A. and Piercy, M. In search of the functional locus of amnesic syndromes. In Human Memory and Amnesia, L. S. CermaK (Editor), pp. 123-137. Lawrence Erlbaum, Hillsdale, NJ, 1982.

14. Kaushall, P. I., Zetin, M. and Squire, L. R. A psychosocial study of chronic, circumscribed amnesia. J. nere. ment. Dis. 169, 383-389, 1981.

15. Kinsbourne. M. and Wood, F. Short-term memory processes and the amnesic syndrome. In Short-term Memory, D. Deutsch and J. A. Deutsch (Editors), pp. 258-291. Academic Press, New York, 1975.

16. Mair, W. G. P., Warrington, E. K. and Weiskrantz, L. Memory disorders in Korsakoff's psychosis. A neuropathological and neuropsychological investigation of two cases. Brain 102, 749-783, 1979.

17. Marslen-Wilson, W. D. and Teuber, H. L. Memory for remote events in anterograde amnesia: redognition of public figures from newsphotographs. Neuropsychologia 13, 353-364, 1975.

18. MCKoOn, G. and RatclifF, R. Priming in episodic and semantic memory. J. verb. Learn. verb. Behav. 18, 463-480, 1979.

19. Meudell, P. R., Northern, B., Snowden, J. S. and Neary, D. long-term memory for famous voices in amnesic and normal subjects. Neuropsychologia 18, 133-139, 1980.

20. Moscovitch, M. Multiple dissociations of function in amnesia. In Human Memory and Amnesia, L. S. C.ERMAK (Editor), pp. 337-370. Lawrence Erlbaum, Hillsdale, NJ, 1982.

21. Sanders, H. I., and Warrington, E. K. Memory for remote events in amnesic patients. Brain 94, 661-668, 1971.

22. SChacter, D. L. and Tulving, E. Amnesia and memory research. In Human Memory and Amnesia, L. S. CermaK (Editor), pp. 1-32. Lawrence Erlbaum, Hillsdale, NJ, 1982.

23. Schacter, D. L. and Tulving, E. Memory, amnesia, and the episodic/semantic distinction. In Expression of Knowledge, R. L. IsaAcson and N. E. Spear (Editors). Plenum Press New York, in press.

24. SChacter, D. L., Wang, P. L., Tulving, E. and Freedman, M. Functional retrograde amnesia: a quantitative case study. Neuropsychologia 20, 523-532, 1982.

25. SCoville, W. B. and Milner, B. Loss of recent memory after bilateral hippocampal lesions. J. Neurol. Neurosurg. Psychiatr. 20, 11-21, 1957.

26. Seltzer, B. and Benson, D. F. The temporal pattern of retrograde amnesia in Korsakoff's disease. Neurology 24, 527-530, 1974.

27. SQuire, L. R. The neuropsychology of human memory. A. Rev. Neurosci. 5, 241-273, 1982.

28. SQuire, L. R. Neuropsychology of ECT. In Electroconvulsive Therapies: Biological Foundations and Clinical Application. W. B. Essman and R. ABrams (Editors), pp. 169-186. Spectrum Publications, New York, 1982.

29. Squire, L. R. Comparisons between forms of amnesia: some deficits are unique to Korsakoff syndrome. $J$. exp. Psychol:: Learning, Memory and Cognition 8, 560-571, 1982.

30. Squire, L. R. and CoHEN, N. J. Memory and amnesia: resistance to disruption develops for years after learning. Behat. Neurol. Biol. 25, 115-125, 1979.

31. SQUIRE, L. R. and COHEN, N. J. Remote memory, retrograde amnesia, and the neuropsychology of memory. In Human Memory and Amnesia, L. CERMAK (Editor), pp. 275-303. Lawrence Erlbaum, Hillsdale, NJ, 1982.

32. Squire, L. R. and CoHEN, N. J. Human memory and amnesia. In Conference on the Neurobiology of Learning and Memory, J. L. MCGough, G. LYNCH and N. M. Weinberger (Editors). Guilford Press, New York, in press.

33. Squire, L. R. and MoORE, R. Y. Dorsal thalamic lesion in a noted case of chronic memory dysfunction. Ann. Neurol. 6, 503-506, 1979.

34. Souire, L. R. and Slater, P. C. Anterograde and retrograde memory impairment in chronic amnesia. Neuropsychologia 16, 313-322, 1978.

35. Squire, L. R., Chace, P. M. and Slatter, P. C. Retrograde amnesia following electroconvulsive therapy. Nature 260, 755-777, 1976.

36. Souire, L. R., Slater, P. C. and ChaCe, P. M. Retrograde amnesia: temporal gradient in very long-term memory following electroconvulsive therapy. Science 187, 77-79, 1975.

37. Squire, L. R., Slater, P. C. and Miller, P. L. Retrograde amnesia and bilateral electroconvulsive therapy. Archs gen. Psychiat. 38, 89-95, 1981.

38. Strain, J. J., Brunschwig, L., Duffy, J. P., Agle, D. P., Rosenbaum, A. L. and Bidder, T. G. Comparison of therapeutic effects and memory changes with bilateral and unilateral ECT. Am.J. Psychiat. 125, 294-304, 1968.

39. Talland, G. A. Deranged Memory. Academic Press, New York, 1965. 
40. Teuber, H. L., Milner, B. and Vaughan, H. G. Persistant anterograde amnesia after stab wound of the basal brain. Neuropsychologia 6, 267-282, 1968

41. Tulving, E. Episodic and semantic memory. In Organization of Memory, E. Tulving and W. Donaldson (Editors), pp. 381-403. Academic Press, New York, 1972.

42. Tulving, E., Schacter, D. L. and StaRK, H. A. Priming effects in word-fragment completions are independent of recognition memory. J. exp. Psychol.: Learning, Memory and Cognition 8, 352 -373, 1982.

43. Victor, M., Adams, R. D. and Collins, G. H. The Wernicke Korsakoff Syndrome. F. A. Davis, Philadelphia. PA, 1971.

44. WARRINGTON, E. K. The double dissociation of short-and long-term memory deficits. In Human Memory and Amnesia, L. S. Cermak (Editor), pp. 6I-76. Lawrence Erlbaum, Hillsdale, NJ, 1982.

45. WOOD, F., EBERT, V. and KINSBOURNE, M. The episodic-semantic memory distinction in memory and amnesia: clinical and experimental observations. In Human Memory and Amnesia, L. S. Cermak (Editor), pp. 167- 193. Lawrence Erlbaum, Hillsdale, NJ, 1982.

46. Zola-Morgan, S. M. and Oberg, R. G. Recall of life experiences in an alcoholic Korsakoff patient: a naturalistic approach. Neuropsychologia 18, 549-557, 1980

\begin{abstract}
Résumé
La capacité à se rappeler des épisodes anciens a été testée chez trois types de malades amnésiques dont la mémnire sémantinue à lonq-terme avait été évaluée nréalablement. Des malades présentant un sundrome de Korsakoff, If cas IA. et des malades soumis à une thêr adeutique nar electrochoc ont tous réussi à se rappeler des épisodes autobiographiques spécifiques en réponse à des indices verbaux simples. Dans de nombreuses conditions, ces sujets ont rëussi la tâche aussi bien que les sujets de contrôle. Leur performance s'est trouvée comparable à celle obtenue dans les lests préalables de la mémoire sémantique à lang terme. Ces résultats s'opposent à l'idée que l'amnésio est un déficit sélectif de la mémoire nour les ênisodes et sugqêrent que la distinction entre mémoire sémantique et mémolre pour les énisorles ne veul éclairer le déficit fondamental de 1'amnésie. L'étude des amnésies ne neut d'ailleurs confirmer ni infirmer la validité de cette distinction dans la mémoire normale.
\end{abstract}

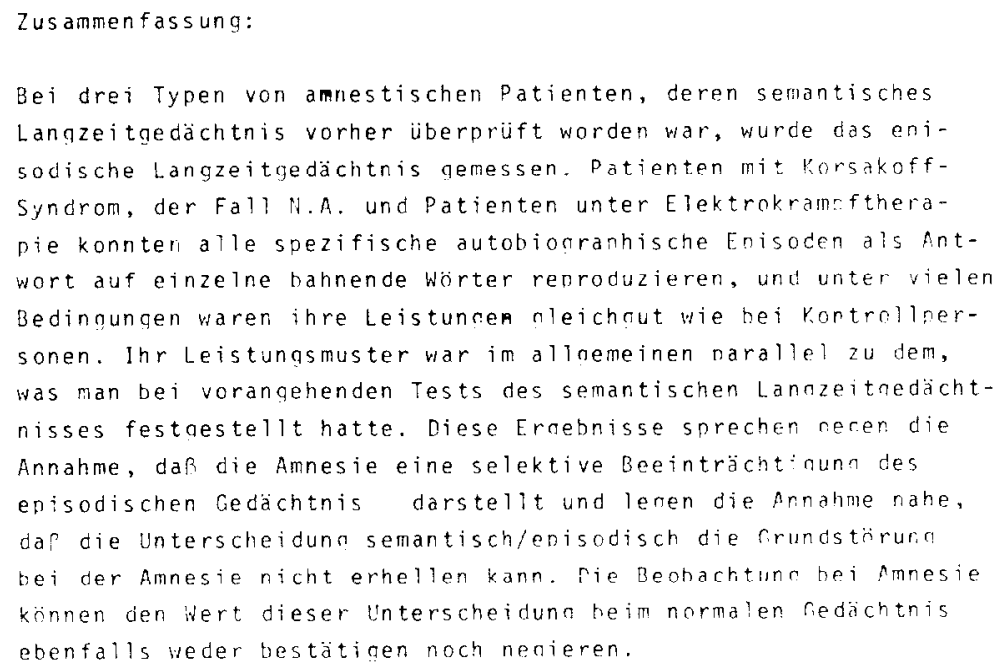

